\title{
Chromosome loss in bi-parental progenies of tetraploid Pacific oyster Crassostrea gigas
}

\author{
Helen McCombie, Sylvie Lapègue, Florence Cornette, Christophe Ledu \\ and Pierre Boudry*
}

Laboratoire de Génétique et Pathologie, Institut Français de Recherche pour l'Exploitation de la Mer (IFREMER), 17390 La Tremblade, France

*: pboudry@ifremer.fr Tel.: +33 5467626 30; fax: +33 546762611

\begin{abstract}
Alterations of chromosome number have been observed in the somatic tissue of Crassostrea gigas diploids and artificial polyploids. Tetraploid oysters with abnormal chromosome numbers in some or all of their tissue are considered undesirable as parents either for triploids (produced via a cross with diploids and of aquacultural interest) or for tetraploid breeding. Aneuploid tetraploid oysters may confer the tendency to lose chromosomes and to revert to lower ploidy levels to their offspring. More directly, their offspring could have a lower ploidy because of potential links between somatic and gametic chromosome loss. The present study evaluated the phenomenon in six bi-parental tetraploid families bred from parents of differing somatic ploidy quality. The offspring were assessed over a year using chromosome counts. Differences between families and parental influence on chromosome loss were evaluated. This showed that chromosome loss occurred at high frequency in all families and that families differed in their composition of ploidy types. Triploidy was observed in four out of the six families. Comparison of data collected at 4 months and 1 year showed no worsening on this time-scale. The incidence of chromosome loss among families suggests a genetic basis to the phenomenon, although a direct relationship between the ploidy quality of the parents and that of the offspring was not observed. The origins and evolution of chromosome loss in polyploid oysters and the implications for breeding are discussed.
\end{abstract}

Keywords: Oyster; Tetraploid; Polyploid; Aneuploid; Cytogenetics; Chromosome; Mitosis; Crassostrea gigas 


\section{Introduction}

Tetraploid oysters are of growing aquacultural importance because they can serve as genitors of hatchery-bred triploid spat (Guo et al., 1996). Triploid spat accounts for a high proportion of hatchery spat production (up to $40 \%$ in the US (J. Davis pers. comm.) now that the aquacultural superiority of triploids has been recognised, notably because of their sterility and improved growth rate (review by Nell, 2002). Triploids have become economically important and so now have tetraploids since the diploid $x$ tetraploid cross ( $2 n$ female $x$ 4n male) provides a more reliable means of producing triploids than chemical induction techniques, and is more acceptable to the consumer (Guo and Allen, 1994; Guo et al., 1996). Tetraploidy in bivalve shellfish has been produced by chemical manipulation of embryogenesis in diploids (Scarpa et al., 1993; Yang et al., 2000) and triploids (Guo and Allen, 1994; He et al., 2000, Eudeline et al., 2000, Supan et al., 2000). However, chemical manipulation has a variable degree of success, producing highly differing percentages of tetraploids between batches, meaning that these require careful sorting to find the tetraploids before they can be used. Once established however, tetraploids should produce diploid gametes (Guo and Allen, 1997) and thus serve to breed tetraploid progenies using $4 \mathrm{n} \times 4 \mathrm{n}$ crosses. All-tetraploid lines could be maintained in this manner providing a basis for selection and reliable ploidy level for the production of genitors for triploids.

Chromosomal instabilities reported in Crassostrea gigas mainly consist of somatic hypoploidy (chromosome loss), associated with inferior growth, in natural and hatcheryproduced diploid juveniles (Leitão et al., 2001a). This aneuploid phenomenon affects 1-3 chromosomes in up to 34\% of the somatic cells (Thiriot-Quiévreux et al., 1992). Other aneuploid chromosome loss phenomena have been observed in somatic cells of triploids, both in the field (Allen et al., 1999; Hand et al., 1999) and in hatchery batches following chemical induction or 2n x 4n crosses (Wang et al., 1999). While the results from the field 
imply that the loss is progressive, leading to mixtures of chromosome numbers within the same animal, work on the $2 n \times 4 n$ progenies suggested that aberrant gametes from the $4 n$ parent produced offspring with the same aneuploid number in all cells. Chromosome loss has also been observed in tetraploid somatic cells (Zhang et al., 2002), where it was associated with clumping of chromosomes and therefore attributed to a segregation problem.

Aneuploidy in diploids has been shown to have a genetic component, which could indicate genetic control or differential susceptibility to an external factor (Leitão et al., 2001b); it affects some chromosomes more than others (Leitão et al., 2001c) and augments in the presence of certain pollutants (Bouilly et al., 2003). The observations on triploids imply that the phenomenon increases with time and environmental stress and may lead to reversion to diploidy (20 chromosomes) in some or all cells (Allen et al., 1999; Hand et al., 1999). Under these circumstances, the animals might lose some of the advantages associated with triploidy. Normally though, triploids are marketed young enough that such problems should not have serious implications. However, if similar mechanisms are at work in tetraploids, the maintenance of tetraploid stocks could be jeopardised by aneuploidy and reversion either with ageing of individuals or across generations.

Negative effects of aneuploidy could have several implications for tetraploids. Although, unlike in diploids (Leitão et al., 2001a), chromosome loss from polyploids does not appear to be associated with size inferiority (Guo and Allen, 1994, Wang et al., 1999), it might bring about the formation of gametes of a lower ploidy level and thus offspring (either triploid or tetraploid) which are not of the desired ploidy class. Chromosome loss to the point of $4 n$ to $3 n$ reversion might also cause infertility. Even if there is no direct effect on the gametes, a similar phenomenon to somatic aneuploidy observed in diploids, with a genetic basis, could confer the likelihood to lose chromosomes to either triploid or tetraploid progeny. 
In the present study, we compare $4 \mathrm{n} x$ 4n families for chromosome number stability. Comparison of families was intended to reveal if any aneuploid genetic effect, similar to that reported in diploids (Leitão et al., 2001b), was apparent in tetraploids. It also enabled us to explore the possibility of selection against chromosome instability, an important point for the future development of tetraploid lines. Examination by chromosome counting allowed us to gain both a quantitative and qualitative picture of the phenomenon. Samples were repeated in time to see whether any deterioration occurred over the first year of life and what validity precocious samples had for later results. This was a means of testing whether early family screening could be effective.

\section{Material and Methods}

Parental tetraploid $(4 n)$ oysters were selected from different $2^{\text {nd }}$ or $3^{\text {rd }}$ generation tetraploid families. Selection was made on the basis of DNA index measured using Feulgen-stained image analysis of gill cell nuclei (Gérard et al., 1994). These measurements were made on non-destructive samples of gill tissue taken under $\mathrm{MgCl}$ anaesthesia and allowed us to choose animals of differing ploidy quality. Sex was determined at the same time. Chromosome counting was not possible on the parents as the method (described below) is destructive. A 'good' quality animal was considered to be one where the DNA index (the ratio between the DNA content of cells of the sample and those of a diploid control) produced a single fine point at 4c (DNA index $=2$ ). Wide or multiple peaks and indices less than 2 could imply chromosome loss from the majority of cells. Parental DNA indices are given with the crossing plan in table 1.

A sample of gill tissue from each parent was preserved in 100\% ethanol and later used to make a microsatellite-based parentage verification of all animals sampled at the first time point in this study (method as in McCombie et al., in press). These analyses, using the 
markers CG49 (Magoulas et al., 1998) and L10 (Huvet et al., 2000), confirmed the absence of contamination of samples from other families within the study or from outside.

Samples of male gametes were also evaluated using Feulgen-stained image analysis. The same appraisal could not be made of female gametes because the presence of yolk caused poor image resolution.

Table 1. Mating design with parental DNA indices (in brackets) calculated from the ratio between the DNA content of gill cells of the sample and those of a diploid control.

\begin{tabular}{lccc}
\hline Parents & $\begin{array}{l}\text { Good Female } \\
(2) \\
\text { (Fine 4n DNA peak) }\end{array}$ & $\begin{array}{l}\text { Poor Female 1 } \\
(1.7-1.9) \\
\text { (Broad 4n DNA peak) }\end{array}$ & $\begin{array}{l}\text { Poor Female 2 } \\
\text { (2-2.3) }\end{array}$ \\
\hline $\begin{array}{l}\text { Good Male } \\
(2)\end{array}$ & GG 'Good-Good' & PG1 & PG2 \\
(Fine 4n DNA peak) & & & PP2 \\
\hline $\begin{array}{l}\text { Poor Male } \\
(1,2.1)\end{array}$ & GP & PP1 & \\
Double‘mosaic' peaks & & & \\
\hline
\end{tabular}

A crossing plan was devised which mated animals of good and poor somatic ploidy quality (table 1). These animals were strip-spawned and crosses performed at a sperm-egg ratio of 200:1. The embryos were transferred to 150 litre larval rearing tanks at 1 hour postfertilisation and raised following a modified protocol of Walne (1974). At 24 hours, an evaluation was made of percentage developing larvae (based on total available eggs) and proportion of normal 'D-shaped' development amongst these. Larvae were fixed progressively on ground oyster shell cultch as they reached the pediveliger stage. The animals which had not reached the pediveliger stage were returned to the larval rearing tanks until they were ready for fixation. This process maintained the maximum variation in development. The total duration of larval rearing ranged from 20 to 24 days.

Samples for chromosome analysis were taken at 4 months and 1 year. At each point, 10 randomly selected animals were sampled per family. Animals were incubated in $0.005 \%$ 
colchicine followed by fixation of the gills in Carnoy's fixative (3:1 absolute ethanol: glacial acetic acid) (Thiriot-Quiévreux and Ayraud 1982). Four months was the first point at which this method, which requires that a minimum size be attained, could be performed. Air-dried slides (Thiriot-Quiévreux and Ayraud 1982) were made from each sample, stained with Giemsa and examined under an Olympus BH2 microscope. Counts of chromosomes per cell were made on 30 similarly well-spread metaphases per animal.

Results were considered in two ways: 1, proportion of abnormal cells and 2, number of chromosomes per cell. This gives a two dimensional picture of aneuploidy. The first estimate is common to work on aneuploidy in diploids (e.g. Thiriot-Quiévreux et al., 1992, Zouros et al., 1996, Leitao et al., 2001a), the second is new and is considered here because the phenomenon we observed could involve very different numbers of missing chromosomes and therefore differences in the extent of chromosome loss per cell. Number of chromosomes per cell was also estimated as the mean number of chromosomes per abnormal metaphase (rather than over all 30 metaphases) per animal.

To take into account possible bias related to the air drying technique, individuals observed with less than $10 \%$ aneuploid cells were classed as tetraploids. A contingency $\chi^{2}$ test was used to test for differences in incidence of tetraploidy (less than $10 \%$ aneuploid cells per animal), aneuploidy (more than $10 \%$ aneuploid cells per animal) and triploidy (modal chromosome number $=30$ ) between families and different parents. Variables were also compared between families, between offspring of different parents and between sampling times using analyses of variance with arc-sine transformations to normalise percentage-based variables.

The different aneuploidy statistics were also examined for their relationship by using linear regression between the number of chromosomes per abnormal cell and the percentage 
of cells affected to test for a worsening of chromosomal loss with increasing frequency of abnormal cells

\section{Results}

All crosses made in this study produced some successful, normal embryos, though hatching rates and percentage normal and abnormal D-larvae at 24 hours were highly variable and different between families (table 2). When the progenies were compared between each pair of families with the same female but different male, there was a consistent higher percentage of abnormal larvae in the progeny of the 'poor' male in all three cases (table 2). However, image analysis of gametes from both males (the 'good' and the 'poor') displayed fine diploid peaks indicating normal mean sperm ploidy in both cases.

Table 2. Hatching rates and normal or abnormal development of larvae of tetraploid families at 24 hours.

\begin{tabular}{|c|c|c|c|c|c|c|}
\hline Family & $\begin{array}{l}\text { Female } \\
\text { Parent }\end{array}$ & $\begin{array}{l}\text { Male } \\
\text { Parent }\end{array}$ & $\begin{array}{l}\text { Initial } \\
\text { number of } \\
\text { Ovules }\end{array}$ & $\begin{array}{l}\text { Hatching } \\
\text { rate } \\
(\%)\end{array}$ & $\begin{array}{l}\text { Normal } \\
\text { Development } \\
(\%)\end{array}$ & $\begin{array}{l}\text { Abnormal } \\
\text { Development } \\
\text { (\%) }\end{array}$ \\
\hline GG & Good female & Good male & 566000 & 20.90 & 70.41 & 29.59 \\
\hline GP & Good female & Poor male & 566000 & 34.45 & 43.59 & 56.41 \\
\hline PG1 & Poor female 1 & Good male & 293000 & 29.01 & 88.24 & 11.76 \\
\hline PP1 & Poor female 1 & Poor male & 293000 & 38.67 & 73.52 & 26.48 \\
\hline PG2 & Poor female 2 & Good male & 213000 & 12.49 & 75.19 & 24.81 \\
\hline PP2 & Poor female 2 & Poor male & 213000 & 15.63 & 69.97 & 30.03 \\
\hline
\end{tabular}


Aneuploidy was considered at different levels, firstly between cells, then within and between animals and finally between groups of animals. The aneuploidy in the observed cells was highly variable. An examination of all the cells counted in the experiment (all animals mixed) shows predominantly (76.9\%) normal cells with 40 chromosomes (figure 1 ), and a secondary peak with 30 chromosomes per cell (5 \%). However, abnormal cells ranged between 20 and 42 chromosomes therefore showing both hypotetraploidy ( $<40$ chromosomes, 20.7\%) and hypertetraploidy (>40chromosomes, $2.4 \%$ ). The composition of animals was then considered to see what cell types different individuals contained.

Figure 1. Frequency of cells with different chromosome numbers throughout the study (across timepoints, families and individuals).

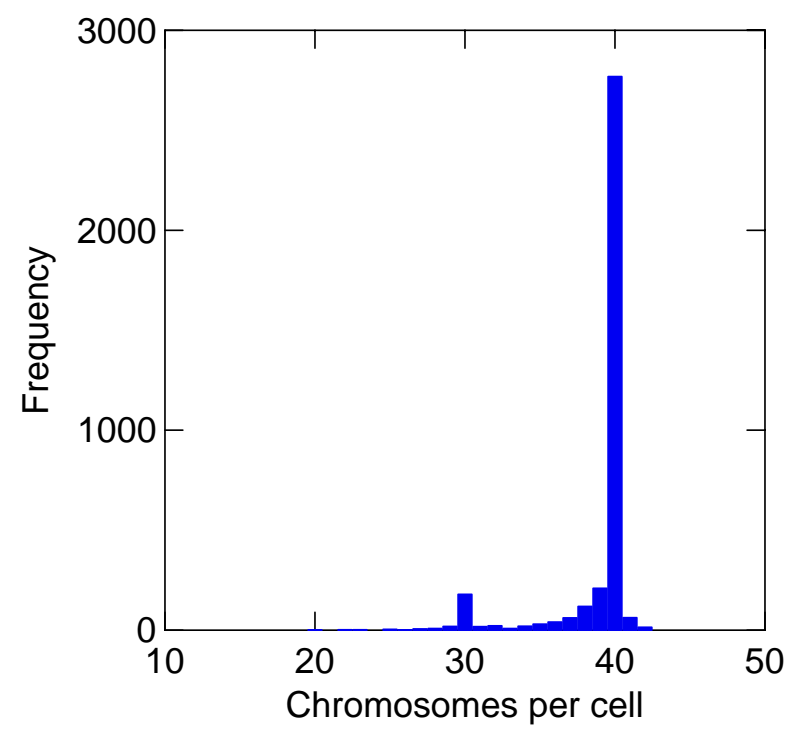

A small proportion of the studied animals (5\% $=6$ individuals/120) were $100 \% 4 n=40$, these were scattered across the families and occurred in all except PP2. However, most animals had at least a small proportion of abnormal cells. These were of varying chromosome number within the animals. Mean aneuploidy per animal was $23 \%$ of cells affected when all 
animals in the study were considered, although the frequency of abnormality ranged from 0$100 \%$ of cells. All animals with $100 \%$ abnormal cells (5.8\% $=7$ individuals/120) were observed to have a triploid modal number, meaning that they had 30 chromosomes in the majority of their cells. These animals were present in the families GG, GP, PG1 and PP1. They had 30 chromosomes in 53-100\% of their cells and their remaining cells contained between 22 and 36 chromosomes, but they had no cells with 40 chromosomes. Peak aneuploidy for the rest of the animals, not including these triploids, was 53\%. The aneuploid cells in these other animals had chromosome numbers ranging from 20-42 but tended to have chromosome numbers closer to 40 (87\% were within the range 35-42).

The relationship between number of chromosomes lost and frequency of aneuploid cells, shown in figure 2, reveals a negative relationship between number of cells affected and number of chromosomes per abnormal cell per animal. The negative relationship is significant even without the influence of the triploid animals (linear regression without triploids $\mathrm{r}^{2}=0.12$ $\mathrm{p}<0.001)$. Therefore, chromosome loss worsens with number of cells affected. However, as time effects were not significant within the limits of the year over which the experiment was conducted, we cannot say that there is a time-related worsening effect. A second important point about figure 2 is the gap that occurs in the data between 16 cells affected (53\%) and 30 cells affected (100\%). This suggests that triploidy and other aneuploidy effects in tetraploids are discrete phenomena. 
Figure 2. The relationship between mean number of chromosomes in abnormal cells per animal and number of abnormal cells per animal. Intact tetraploids with $100 \%$ of cells $4 \mathrm{n}=40$ are not included. Regression significant $\mathrm{r}^{2}=0.12 \mathrm{p}<0.001$ (not including triploids).

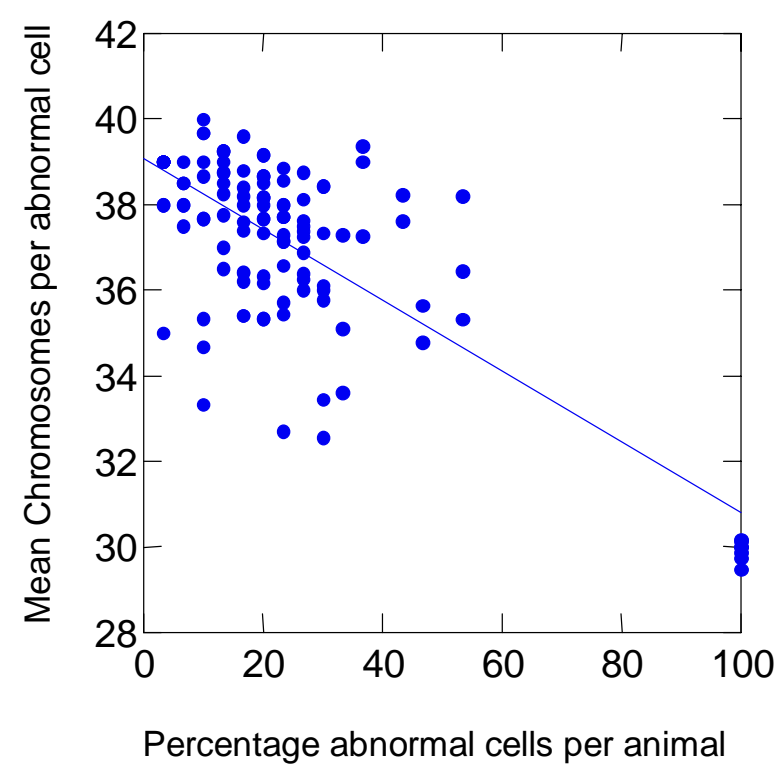

Family differences were revealed in the analysis of incidence of animals of the different classes: tetraploid, aneuploid, triploid ( $\mathrm{p}=0.012$, contingency $\chi^{2}$ test). A difference was also noted in the incidence of animals with $100 \%$ non-tetraploid cells. These majority triploid animals occurred in four out of the six families (figure 3). The two families without these triploids were bred from the same maternal parent. Family and parent effects were not significant for any continuous aneuploidy measure (\% cells affected per animal, mean number of chromosomes missing per cell or per abnormal cell) and there was no significant change in these aneuploidy statistics between the two time points. Analyses on continuous aneuploidy measures were repeated excluding the triploid animals but neither genetic or time effects were significant. 
Figure 3. Occurrence of different classes of animal in the different families. Triploid: all cells abnormal with 30 chromosomes or a number close to 30 . Aneuploid intermediates: between $10 \%$ and $53 \%$ cells aneuploid (chromosomes $\neq 40$ ). Tetraploid: No or less than $10 \%$ cells aneuploid. $n=20$ per family.

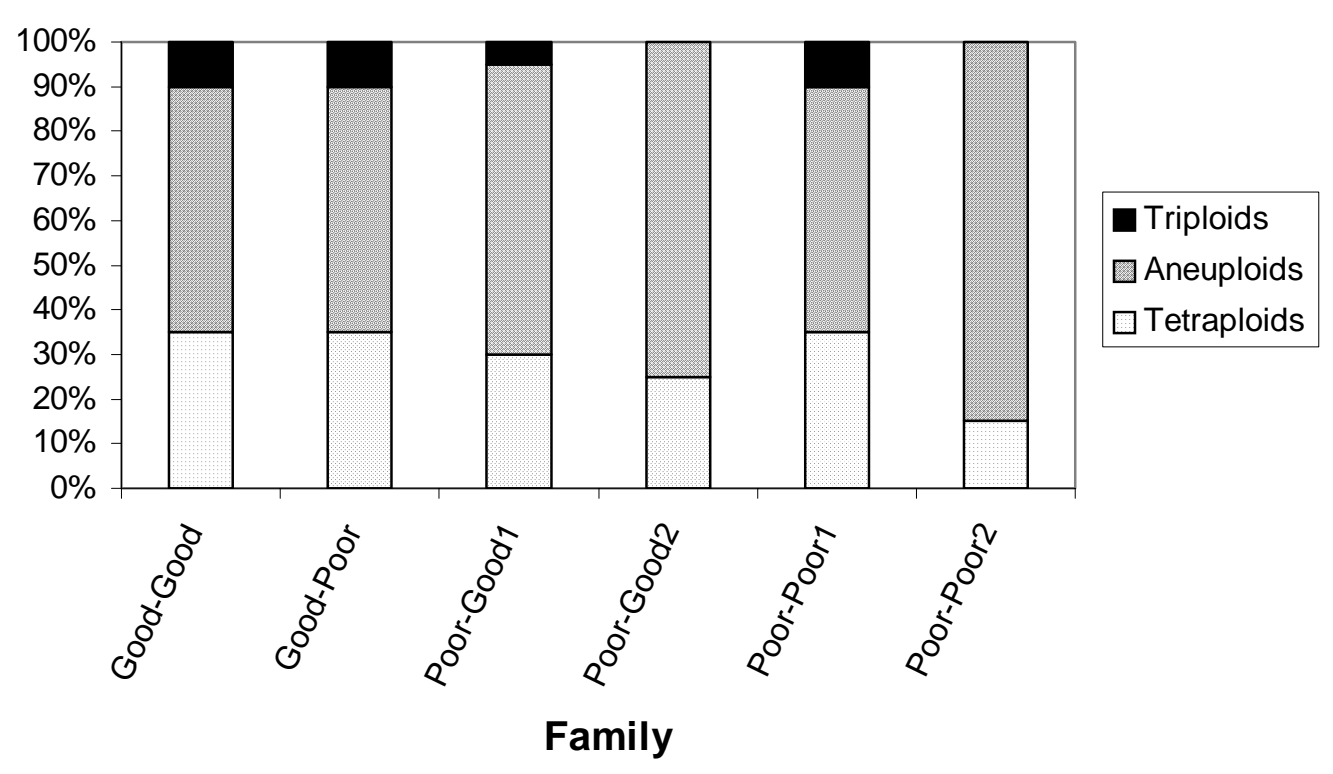

Aneuploidy other than in the triploid animals was compared between the families containing these triploids and the other families to see if chromosome loss was higher in the families with triploids. This could have provided an indication that the aneuploid chromosome loss observed led to triploidy. However there was no difference in aneuploidy between these groups, implying once again that the majority triploids had not degraded from tetraploidy via the aneuploidy otherwise observed. As microsatellite results showed that the hypothesis of contamination was unfounded, we concluded that these triploids had come from the crosses made but had become triploid by another means.

\section{Discussion}

The nature and origins of chromosome loss in tetraploid oysters

Somatic aneuploidy is thought to arise from non-disjunction of chromosomes at mitotic metaphase (Bond and Chandley, 1983), and such mistakes, leading to reciprocal gain and loss 
of chromosomes in the daughter cells, occur at a low level in nature (Wenger, 1990). The variable level and linking of this phenomenon to size differences in oysters (Leitão et al., 2001a) indicated that the aneuploidy observed in oysters went over and above a natural background level. Further study revealed that aneuploidy was not only related to an animal's size but was also influenced by its genetic background (Leitão et al., 2001b). In the present study, we observed chromosome loss (and gain) in cells of tetraploid oysters. Our results show a markedly higher peak somatic aneuploidy level (53\%) than has previously been reported in diploids (34\%, Thiriot-Quiévreux et al., 1992) even when our 100\% non-tetraploid animals were not considered.

It must be noted that tetraploidy is artificial in oysters and may therefore create a situation of increased instability. Even though the animals in our study were from crosses and not from chemical induction, the ancestors of our experimental material were produced by chemical manipulation of embryonic cells with a lower ploidy level and therefore a lower cell size. Low cell volume to nuclear ratios have been previously held responsible for failed mitotic development in high ploidy constructs (Guo and Allen, 1994; Peruzzi and Guo, 2002). Abnormal mitosis was implied by the metaphase observations of Zhang et al., (2002) on tetraploid mitoses, who reported unnatural clumping of chromosomes possibly arising from or causing uneven chromosome segregation.

In our study, the hypothesis of uneven mitotic division is supported by the presence of cells of hypertetraploid ( $>40$ chromosomes) numbers. What cannot be directly understood from the results is what happens to aneuploid cells after the visible countable stage at which we observe them. An observed metaphase cell has already survived from a hypothetical uneven division to the next mitotic metaphase when we can view it. What happens next? Do aneuploid cells divide again? In this case the abnormality would propagate. In the case of aneuploidy in diploids, each loss of a chromosome corresponds to progressive haploidisation 
(Zouros et al., 1996). This may be detrimental or lethal to the cell because of disrupted gene doses or lethal effects of unmasked alleles. Over a certain percentage of cells affected this could become lethal to the animal, explaining why the percentage aneuploidy is not generally seen to exceed around 30\% in diploids (Leitão et al., 2001a). In a polyploid, a greater buffer exists due to the multiple copies of each chromosome. A cell may be able to bear chromosome loss better for this reason and an animal likewise may be able to survive with a higher percentage of aneuploid cells. Our results support the idea of aneuploidy tolerance by polyploids because we found a higher level of chromosome loss and percentage aneuploidy than in diploids. Further understanding of the implications of tetraploid chromosome loss and its similarity with the diploid phenomenon could be gained in the future with chromosome marking studies (e.g. Leitao et al., 2001c; Leitao et al., in press).

The unusual frequency of triploid cells (the second most common chromosome number after 40 in this study) might be interpreted as a mark of stability at multiples of ten or even that whole sets of ten could be lost together during abnormal mitosis. However, these cells are mostly present in individuals that are majority triploids with 30 as their basic chromosome number and which have no cells with 40 chromosomes. This contrasts with the other animals in our study where triploid cells were no more frequent than other aneuploid numbers. In figure 2 we see that there are no animals with percentages of aneuploidy between 53\% and $100 \%$. The $100 \%$ animals were those with a majority of triploid cells and the lower percentages corresponded to animals with aneuploid cells which had variable numbers, generally higher than 30. Intermediates between triploids and these 'aneuploid tetraploids' did not appear, which suggests that there are in fact two chromosome loss phenomena in the study and that these are not linked.

A more likely explanation for the presence of these triploids, than gradual degradation from tetraploidy, is a gametic effect. Komuru et al. (1995) examined sperm in tetraploid 
mussels by electron microscopy and judged that they should be capable of normal fertilisation. Our own study of ploidy of male gametes showed these as 2 n (haploid of $4 n$ ) as expected, although the image analysis methods may lack accuracy for sperm. Previous results using flow cytometry have given similar expected values for sperm from tetraploid C. gigas (Guo and Allen, 1995). However, Wang et al. (1999) suggested that segregation error in male C. gigas gametes could explain non-triploid progenies of $2 \mathrm{n} \times 4 \mathrm{n}$ crosses and a similar influence may be at work here. Female gametes were not studied for ploidy in the present study, although a previous study (Guo and Allen, 1997) showed meiotic divisions in eggs from tetraploids to be balanced, giving diploid gametes. Multivalents were formed during meiosis however, indicating a potential to produce irregular gametes on the female side. Stiles and Choromanski (2002) highlighted variation and abnormalities in naturally occurring female gametes of diploid Crassostrea virginica, which may lead to abnormal offspring. Female gametic development is therefore already likely to show abnormalities without prior polyploidisation. In the present study, the meiotic divisions take place with twice as much genetic material as natural diploids, which could further destabilise the development and increase the likelihood of irregular gametes. For parental animals to produce a triploid in the present circumstances, some of the animals would need to have had haploid gametes, as a natural diploid animal would. These, combined with a tetraploid mate, would produce triploids. The microsatellite markers used to test offspring for extra-experimental contamination indicated the contribution of both tetraploid parents to these triploid offspring. Although in most cases homozygosity or common alleles between certain male/female combinations meant the microsatellites could not be used to see which parent may have only contributed one haploid genome rather than two to triploid progeny, this was possible with one triploid individual. This triploid came from the family 'good-poor' and had two alleles from the paternal parent but only one from the maternal parent. If the origin of the triploidy is 
gametic, then in this case it was the female that contributed the haploid gametes. Female influence on offspring quality was also suspected in the case of the two families with no triploids which had the same female parent (figure 3).

\section{Genetics and Potential for selection}

Evidence for a genetic basis to the aneuploidy phenomenon has already been suggested in diploids (Leitão et al., 2001b). The present study implies a genetic influence on chromosome loss in tetraploids but also indicates that the fundamental reasons for the problem may be different. The quantitative aneuploidy measurements did not distinguish the families in this study as they had in certain diploid groups (Leitão et al., 2001b). A principal reason for this could have been the high variation observed, both in percentage of cells affected and in chromosomes lost. This variation could have masked any family or time effects. Enlargement of sample sizes was not practical using the present technique because of the large time investment required for counting the chromosomes. Direct genetic or family effects on aneuploidy were therefore not clear. The quality of an offspring batch could not be judged by the quality of its parents either, but the families were different for proportions of different classes and the incidence of triploids. This suggests that the appraisal of families is more useful from a practical perspective than is that of genitors. The screening of families for triploids and any other unwanted aberrations could be a good strategy, leading to the early elimination of 'bad families'. From this point of view, the present results show that the screening at 4 months is just as useful as that at one year and space could therefore be saved by discarding poor families early.

Despite the presence of aneuploidy and triploidy, the progenies of these $4 n x 4 n$ crosses are lower in non tetraploids than are (generally) the progenies of induction 
experiments (Guo and Allen, 1994; Eudeline et al., 2000; He et al., 2000; Allen et al., 2003), indicating that $4 \mathrm{n} \times 4 \mathrm{n}$ crosses represent a good means of propagating tetraploids.

\section{Conclusions}

Somatic aneuploidy occurs in tetraploids to a much greater extent than in natural diploids of Crassostrea gigas. Aneuploidy phenomena took two distinct forms: 1, change of chromosome number, usually (though not exclusively) through chromosomal loss, in up to just over half of the metaphase cells examined, or 2, all cells examined had triploid or near triploid complements. The present data suggest that these situations arise through different mechanisms, and in the light of previous studies, we suspect that the triploids in the progenies were due to irregular gametes. The other aneuploid tetraploids, on the other hand, probably arise from mitotic mistakes, as in diploid aneuploidy, where only a percentage of cells are affected. Tetraploid aneuploidy may be more profound than diploid aneuploidy because the greater amount of genetic material increases instability and/or because a greater percentage loss can be tolerated. The present study only covers aneuploidy of tetraploids in their first year, and though no relationship with time was found, this may develop as animals age further. It would therefore be useful to re-evaluate the same families over a longer time-span to understand the dynamics of chromosome loss better. Another important next step is to study the gametes and the possibility of transfer of the aneuploidy phenomenon between somatic and gametic tissues. Development of a means of screening gametes could lead to a better way of selecting parents and producing high quality, stable tetraploid lines. 


\section{Acknowledgements}

We would like to thank Pascal Phelipot, Raphaël Brizard and Serge Heurtebise at Ifremer La Tremblade for the care and preparation of the animals used in this study, for their technical assistance with the crosses made and their advice on larval rearing and micro-nursing of polyploids. Our thanks also to André Gérard and Philippe Goulletquer for their support and encouragement. H. McCombie is funded by an IFREMER postdoctoral grant. 


\section{References}

Allen, Jr., S.K., Howe, A., Gallivan, T., Guo, X., DeBrosse, G., 1999. Genotype and environmental variation in reversion of triploid Crassostrea gigas to the heteroploid mosaic state. J. Shellfish Res. 18, 293 (abstract).

Allen, Jr., S.K., Erskine,A.J., Walker, E.J., DeBrosse, G.A., 2003. Production of Tetraploid Suminoe oysters Crassostrea aeiakensis. In: Book of Abstracts. Genetics in Aquaculture VIII, 9-15 November 2003, Puerto Varas, Chile. International Association for Genetics in Aquaculture. 44.

Bond, D.J., Chandley, A.C., 1983. Aneuploidy. Oxford Monographs on Medical Genetics No. 11. Oxford University Press, Oxford, UK.

Bouilly, K., Leitão, A., McCombie, H., Lapègue, S., 2003. Impact of atrazine on aneuploidy in Pacific oysters, Crassostrea gigas. Environmental Toxicology and Chemistry, 22, 219-223.

Eudeline, B., Allen, Jr., S.K., Guo, X., 2000. Optimization of tetraploid induction in Pacific oysters, Crassostrea gigas, using first polar body as a natural indicator. Aquaculture 187, 73-84.

Gérard, A. Naciri, Y., Peignon, J-M., Ledu, C., Phélipot, P. Noiret, C., Peudenier, I., Grizel, H., 1994. Image analysis: a new method for estimating triploidy in commercial bivalves. Aqua. Fish. Man. 25, 697-708.

Guo, X., Allen Jr., S.K., 1994. Viable tetraploids in the Pacific oyster (Crassostrea gigas Thunberg) produced by inhibiting polar body 1 in eggs from triploids. Mol. Mar. Biol. Biotech. 3, 42-50.

Guo, X., Allen, Jr., S.K., 1995. Tetraploid Pacific oysters (Crassostrea gigas Thunberg) have high fecundity despite multivalent formation during meiosis. J. Shellfish Res. 14, 267 (abstract). 
Guo, X., Debrosse, G.A., Allen, Jr., S.K., 1996. All triploid oysters (Crassostrea gigas Thunberg) produced by mating tetraploids and diploids, Aquaculture 142, 149-161.

Guo, X., Allen, Jr., S.K., 1997. Sex and meiosis in autotetraploid Pacific oyster, Crassostrea gigas. Genome 40, 397-405.

Hand, R.E., Nell, J.A., Reid, D.D., Smith, I.R., Maguire, G.B., 1999. Studies on triploid oysters in Australia: effect of initial size on growth of diploid and triploid Sydney rock oysters, Saccostrea commercialis (Iredale \& Roughley). Aquaculture Res. 30, 35-42.

He, M.X., Lin, Y.G., Shen, Q., Jiang, W.G., 2000. Production of tetraploid pearl oyster (Pinctada martensii Dunker) by inhibiting the first polar body in eggs from triploids. J. Shellfish Res. 19, 147-151.

Huvet, A., Boudry, P., Ohresser, M., Delsert, C., Bonhomme, F., 2000. Variable microsatellites in the Pacific cupped oyster Crassostrea gigas and other cupped oyster species. Anim. Genet. 37, 71-72.

Komaru, A., Scarpa, J., Wada, K. T., 1995. Ultrastructure of spermatozoa in induced tetraploid mussel Mytilus galloprovincialis (Lamark). J. Shellfish Res. 14, 405-410.

Leitão, A., Boudry, P., Thiriot-Quiévreux, C., 2001a. Negative correlation between aneuploidy and growth in the Pacific oyster Crassostrea gigas: ten years of evidence. Aquaculture 193, 39-48.

Leitão, A., Boudry, P., McCombie, H., Gérard, A., Thiriot-Quiévreux, C., 2001b. Experimental evidence for a genetic basis to differences in aneuploidy in the Pacific oyster (Crassostrea gigas). Aquat. Living Resour. 14, 233-237.

Leitão, A., Boudry, P., Thiriot-Quiévreux, C., 2001c. Evidence of differential chromosome loss in aneuploid karyotypes of the Pacific oyster, Crassostrea gigas. Genome 44, 735737. 
Leitão, A., Chaves, R., Santos, S., Guedes-Pinto, H., Boudry, P., Restriction Enzyme Digestion Chromosome Banding in Crassostrea and Ostrea species: Comparative karyological analysis within Ostreidae. In press. Genome.

Magoulas, A., Gjetvaj, B., Terzoglou, V., Zouros, E., 1998. Three polymorphic microsatellites in the Japanese oyster, Crassostrea gigas (Thunberg). Anim. Genet. 29, 63-72.

McCombie, H., Ledu, C., Phelipot, P., Lapègue, S., Boudry, P., Gérard, A., A complementary method for the production of tetraploid Crassostrea gigas using crosses between diploids and tetraploids with Cytochalasin B treatments. In press. Marine Biotechnology.

Nell, J. A., 2002. Farming Triploid Oysters. Aquaculture 210, 69-88.

Peruzzi, S., Guo, X., 2002. Tetraploid induction by meiosis inhibition with cytochalasin B in the dwarf surfclam, Mulinia lateris Say : Effects of temperature. J. Shellfish Res. 21, 677-684.

Scarpa, J., Wada, K.T., Komura, A., 1993. Induction of Tetraploidy in Mussels by Suppression of Polar Body Formation. Nippon Suisan Gakkaishi 59, 2017-2023.

Stiles, S., Choromanski, J., 2002. Trends in genetics of bivalve mollusks: A review. In: ICES Statutory Meeting Proceedings 2002, Copenhagen, Denmark, October 2002. ICES Copenhagen, Denmark. C.M. 2002/U:11 28pp.

Supan, J.E., Allen, Jr., S.K., Wilson, C.A., 2000. Tetraploid eastern oysters: An arduous effort. J. Shellfish Res. 19, 655 (abstract)

Thiriot-Quiévreux, C., Ayraud, N., 1982. Les caryotypes de quelques espèces de bivalves et gastéropodes marins. Mar. Biol. 70, 165-172. 
Thiriot-Quiévreux, C., Pogson, G.H., Zouros, E., 1992. Genetics of growth rate variation in bivalves: aneuploidy and heterozygosity effects in a Crassostrea gigas family. Genome 35, 39-45.

Walne, P.R., 1974. Culture of bivalve molluscs: fifty years experience at Conwy. Whitefriars Press Ltd, London, 189 pp.

Wang, Z., Guo, X., Allen, Jr., S.K., Wang, R., 1999. Aneuploid Pacific oyster (Crassostrea gigas Thunberg) as incidentals from triploid production. Aquaculture 173, 347-357.

Wenger, S.L., Golden, W.L., Dennis, S.P., Steele, M.W., 1984. Are the occasional aneuploid cells in peripheral blood cultures significant? Am. J. Med. Genet. 19, 715-719.

Yang, H., Zhang, F. and Guo, X., 2000. Triploid and tetraploid Zhikong Scallop Chlamys farreri Jones \& Preston, produced by inhibiting polar body 1. Mar. Biotech. 2, 466-475. Zhang, Q., Howe, A., Chandler W., Allen Jr., S.K., 2002. Cytogenetic mechanism for reversion of triploids and tetraploids to heteroploid mosaics in Crassostrea gigas Thunberg. In: Book of Abstracts. World Aquaculture Society meeting April 23-27 2002 Beijing, China.

Zouros, E., Thiriot-Quiévreux, C., Kotoulas, G., 1996. The negative correlation between somatic aneuploidy and growth in the oyster Crassostrea gigas and implications for the effects of induced polyploidization. Gen. Res. 68, 109-116. 